\title{
Governamentalidade neoliberal e o desafio de uma ética/estética pós-identitária LGBT na educação
}

\section{Neoliberal governmentality and the challenge of a $L G B T$ post-identitarian ethics/aesthetics in education}

\author{
Jamil Cabral Sierra ${ }^{1}$ \\ Maria Rita de Assis César ${ }^{2}$
}

\begin{abstract}
RESUMO
Este trabalho combina duas pesquisas teóricas e pretende estudar a relação que vem se estabelecendo, na atualidade, entre a ideia de diversidade sexual (e seus desdobramentos no campo da política, dos movimentos sociais e da educação) e os dispositivos anátomo-bio-políticos que configuram os atuais mecanismos de governamentalidade, os quais visam capturar as diferenças sexuais, alçando-as ao campo da normalização e da heteronormatividade. A partir desse pressuposto, o texto organiza-se em dois momentos: o primeiro deles visa mostrar como os sujeitos LGBT (Lésbicas, Gays, Bissexuais, Travestis, Transexuais e Transgêneros) vêm sendo produzidos tomando-se como referência a "viabilidade-moral-econômica" de seus corpos e de suas práticas sexuais e afetivo-amorosas. Com esse argumento pretendemos pensar como, na contemporaneidade, as formas de governamento dos sujeitos da diversidade sexual têm se dado a partir de uma relação de parceria entre os movimentos sociais e o Estado. No segundo momento, valemo-nos da noção de ética/estética da existência em Foucault, para mostrar as tensões presentes nesse empreendimento biopolítico que promove uma espécie de captura da diferença sexual, deixando, assim, pouco espaço para a constituição de outros modos de vida. Nosso objetivo é o de promover deslocamentos em relação à lógica identitária, a partir do questionamento da teorização
\end{abstract}

DOI: $10.1590 / 0104-4060.36464$

1 Universidade Federal do Paraná, Setor Litoral. Matinhos, Paraná, Brasil. R. Jagariaíva, nº 512 - Caiobá. CEP: 83600-000.

2 Universidade Federal do Paraná. Setor de Educação. Curitiba, Paraná, Brasil. R. General Carneiro, no 460. CEP: 80060-150. 
político-educacional LGBT. Trata-se de desvincular tal produção teórica do modelo identitário que sustenta a atual noção de diversidade sexual, em favor de um pensamento que nos permita vislumbrar outros modos de vida homossexuais.

Palavras-chave: governamentalidade; estética da Existência; LGBT; educação.

\begin{abstract}
This paper is the outcome of the combination of two theoretical researches and it intends to analyze the relationship that has been recently established between the idea of sexual diversity (and its consequences in the political field, in social movements and in education) and the anatomo-bio-political apparatuses which configure the current governmental mechanisms that aim at the capture of sexual differences, placing them in the field of normality and heteronormativity. Once this theoretical assumption is taken, the text is organized and developed into two moments: the first one intends to show how the production of LGBT (lesbian, gay, bisexual, and transgender) subjects has been contemporarily activated thru the pattern of the "moral-economic-viability" of their bodies, sexual, loving and affective practices. By means of this reasoning, we try to think how contemporary forms of governing the subjects of sexual diversity have been developed in the course of a certain partnership between social movements and the Brazilian State. In the second moment, we employ some Foucauldian notions such as ethics/ aesthetics of existence in order to highlight the tensions that pervade the biopolitical mechanisms which promote the capture of sexual difference, leaving almost no space for the constitution of another ways of living. The paper intends to produce some theoretical displacements in the prevailing identity logics, developing a critical questioning of LGBT educational and political theorizations. In other words, we aim at breaking the bounds that bind together the identity model and actual policies of sexual diversity, in order to think about other homosexual ways of living.
\end{abstract}

Keywords: governmentality; aesthetics of existence; LGBT; education.

O que pretendemos empreender, neste trabalho, com a ajuda de Foucault, é analisar as formas atuais de governamentalidade ${ }^{3}$ dos sujeitos LGBT ${ }^{4}$, es-

3 A noção de "governamentalidade" está sendo usada aqui conforme análise, feita por Foucault (2008b), de como se constituíram no âmbito do estado moderno novos mecanismos de vigilância, controle e intervenção do Estado sobre a vida das populações, frutos de novas estratégias entre o Estado, a economia política e os dispositivos de seguridade.

4 Atualmente, no Brasil, tem-se usado, tanto no âmbito das políticas públicas como na esfera dos movimentos sociais que defendem as causas ligadas a gênero, sexualidade e orientação sexual, 
pecialmente no contexto brasileiro, bem como as estratégias biopolíticas que encerram essas vidas na forma de sujeitos de direito para dar a elas a oportunidade de ingresso à normalidade e seus supostos benefícios: direitos, deveres, bem-estar, sucesso, dignidade, respeito, legalidade e legitimidade. Assim, queremos problematizar os discursos sociais, políticos e educacionais que conformam os sujeitos da diversidade sexual e que impõem a eles um tempo e um lugar na ordem político-social e, por consequência, um tempo e um lugar na ordem escolar-educacional. Para isso, estabelecemos dois argumentos nesse texto. O primeiro deles tem a ver com os processos biopolíticos de captura das subjetividades LGBT e, o segundo, com as formas de resistência possíveis de serem criadas diante dos limites que conformam as subjetividades LGBT na lógica objetivadora das identidades.

\section{Governamentalidade neoliberal e as identidades LGBT}

O primeiro argumento que queremos problematizar refere-se à noção de viabilidade-moral-econômica (SIERRA, 2013) dos sujeitos LGBT. Essa ideia tem a ver com as formas de produção de corpos e vidas ajustados aos processos de classificação, correção e normalização que impõem aos sujeitos LGBT um modo de vida operado a partir da heteronormatividade e que institui a lógica identitária como recurso à inclusão na esfera jurídica, social e educacional. Para tanto, os sujeitos LGBT precisam ajustar-se a dois princípios: a) a uma certa moral, que prescreve quais corpos e quais práticas sexuais e afetivo-amorosas são corretas, honradas, saudáveis, seguras e aceitáveis diante tanto das recomendações dos próprios movimentos sociais quanto das políticas públicas de Estado; b) a uma certa economia ${ }^{5}$, que institui quais corpos e quais práticas

a sigla LGBT para designar este conjunto populacional abarcado tanto pelas políticas públicas como pelas ações dos movimentos sociais. Essa sigla, que outrora já fora "GLS" e "GLBT", sedimentou-se nos anos 2000 como grande representação do movimento de homossexuais, o que acabou por estender seus domínios para além da esfera político-social, já que, hoje, ela se faz aparecer em campos da educação, das artes, da cultura, da economia, do turismo, da moda, da literatura etc. No decorrer deste texto, portanto, usaremos "LGBT" toda vez que nos referirmos a "lésbicas, gays, bissexuais, travestis e transexuais”. Para saber mais sobre essas siglas, ver Fachini (2005).

5 Essa moral e essa economia - noções que aqui estão conectadas ao conceito de "capital humano" desenvolvido por Foucault (2008a) - são responsáveis pela produção de identidades normatizadas que, em território heteronormativo, atendem agora não só aos desígnios morais, mas, também, aos aparatos do mercado que regulam a produção desse sujeito como ativamente econômico e rentável. Para Gadelha Costa (2009), quando falamos em uma economia política, estamos nos 
sexuais e afetivo-amorosas atendem ao projeto de utilidade-rentabilidade que a ordem do consumo e do trabalho neoliberais apregoam como necessárias ao projeto de consolidação do sujeito de direito e de sua consequente e paradoxal exclusão pelo mesmo sistema jurídico-econômico que o criou e diz inclúi-lo (BUTLER, 2003).

A assunção de uma identidade carimbaria esse sujeito, da forma como temos percebido, como um corpo-em-viabilidade, uma vida-em-viabilidade e, diante dessa sua virtual utilidade-rentabilidade, um corpo capaz de lutar por direitos até então não reconhecidos a ele. Revelar-se gay, por exemplo, significa, nesse contexto, deixar de ser veado ${ }^{6}$ para constituir-se viável, assumir-se útil-rentável moral e economicamente e, com isso, tentar a chance de trocar de domínio: da abjeção para a aceitação. A produção de uma viabilidade-moral-econômica ${ }^{7}$, que começa a ser desenhada nos anos 1970, com suas lutas pelo outing $^{8}$, adquire, na contemporaneidade, sua radicalização no momento em que movimentos sociais e Estado passam a configurar uma parceria (SIERRA, 2013) disposta a reparar, sob o princípio da tolerância e da inclusão, os corpos de LGBTs, traduzindo-os numa identidade segura e reconhecível, bem como viabilizando-os por meio dos compromissos de cidadania e direitos reivindicados pelos sujeitos da diversidade sexual e garantidos pelo Estado.

Evidentemente, essa busca por uma identidade reconhecível já havia passado pelo movimento feminista no momento em que se buscava categorizar a mulher como uma espécie de sujeito universal do feminismo. Foi preciso algum trabalho para deslocar esse entendimento universalista de que tratava esse feminismo descrito acima. Mulheres completamente em flerte com as teorizações foucaultianas da época começam, em fins dos aos 1970, a deslocar essa, até então, noção do feminismo. Adrienne Rich (1993), Gayle Rubin (1993), Monique Wittig (1993), Guacira Lopes Louro $(1995,1998)$ foram algumas que se debruçaram na tarefa, cada uma ao seu modo, em seu tempo e de seu lugar,

referindo ao "[...] trabalho exercido pelos indivíduos como uma conduta econômica, e de tentar entender como essa conduta é praticada, racionalizada e calculada por aquele que a exerce." (p. 176). Esse argumento, peça-chave na análise do objeto dessa tese, ainda será melhor descrito e desenvolvido à medida em que avanço na escrita do texto, especialmente na primeira parte.

6 "Veado" é uma expressão que, no Brasil, é utilizada para se referir aos homossexuais masculinos de forma pejorativa.

7 Para um detalhamento maior dessa ideia, ver Sierra (2013).

8 O termo outing ("sair do armário", como ficou conhecida a expressão em português) começou a ser usado nos anos 1970, nos Estados Unidos, como forma de chamamento de homossexuais a abandonarem o closet (armário), como estratégia política e de militância. O filme Milk (2008), de Gus Van Sant, mostra bem esse momento da história da militância homossexual americana. Mais informações sobre o filme ver em: <http://www.imdb.com/title/tt1013753/>. Acesso em: 19/07/2011. 
de questionar os fundamentos dessa compreensão de mulher e apontar novas possibilidades teóricas e linguísticas para o feminismo em contraposição ao que pensavam as feministas anteriores. E desse deslocamento na teorização feminista é que resultam, mais recentemente também, os aportes pós-estruturalistas da Teoria Queer ${ }^{9}$, em trabalhos como, por exemplo, de Butler (1993, 1999, 2003), Lauretis (1991), Spargo (2007) e Preciado (2002, 2009, 2011).

É bem por isso que nos interessa justamente captar esse momento que vê sedimentar a luta e a teorização político-identitária LGBT e seus efeitos no campo escolar-educacional, a partir da parceria entre movimentos sociais e Estado ${ }^{10}$, bem como reverberar as contracorrentes que servem de inspiração, sobretudo a partir de Foucault, para ensaiar outras formas de luta e outras possibilidades de vida.

É claro que quando questionamos o pensamento que opera a partir das identidades e das conquistas jurídicas e civis a ela associadas não negamos seus avanços políticos e sociais, tampouco negamos os efeitos que seus discursos e suas práticas promoveram/promovem no combate à LGBTfobia ${ }^{11}$, ao machismo, ao sexismo. Reconhecemos tais deslocamentos e os compreendemos como uma possibilidade de reivindicação. No entanto, não podemos deixar de apontar como essa noção contemporânea de diversidade sexual congela o sujeito numa identidade reconhecível, num corpo traduzível, selando outras potencialidades de vida que o próprio movimento LGBT poderia experimentar, inclusive no que se refere à inserção de sua população na escola.

É bem sabido que a escola tem se constituído como grande lugar em que se processam as produções de verdade sobre o sexo, o gênero e a sexualidade. É bem sabido, também, que a escola e demais instâncias de educação formal têm se dedicado, através de seus porta-vozes, de seus especialistas e agregados (médicos, enfermeiras, psicólogos, psicopedagogos, terapeutas de toda sorte) a falar a verdade sobre o sexo e a produzirem, por meio de seus saberes, quais são os corpos inviáveis e quais são os corpos viáveis. Em outros termos,

9 “Teoria Queer" quer representar a unificação dos estudos gays e lésbicos que, surgidos na esteira do movimento feminista, vão tensionar ainda mais a estabilidade e a rigidez das identidades culturais, especialmente a partir da problematização que faz esta teoria das identidades de gênero/ sexuais.

10 Para uma análise mais detalhada dessas relações de parceria entre Estado e movimentos sociais ver Sierra (2013).

11 Usamos aqui a expressão "LGBTfobia" como forma de marcar que os processos de exclusão e preconceito sexuais se dão, no contexto atual, também a partir dessa segmentação identitária que venho anunciando. Desse modo, "LGBTfobia" diz respeito aos mecanismos de produção da violência de gênero e sexuais que interceptam as vidas de gays (homofobia), de lésbicas (lesbofobia), de bissexuais (bifobia), de travestis e transexuais (transfobia). 
[...] o objetivo das novas formas de governamento dos corpos e das almas - sejam elas ativadas por meio de políticas públicas estatais ou por meio das demandas flexíveis e descentradas do mercado econômico, sem deixar de mencionar que muitas vezes tais estratégias de atuação apresentam-se de maneira combinada - é a aquisição de competências adequadas ao mercado neoliberal, tendo em vista a produção de corpos viáveis. (CÉSAR, 2010a, p. 232).

A escola se torna, assim, um dos espaços privilegiados de produção das identidades, já que se a pauta dos movimentos sociais, antes de tudo, é o reconhecimento de direitos, o direito à educação é, sobremaneira, seu carro-chefe e seu lugar de inclusão por excelência. ${ }^{12}$ Desse modo, as lutas identitárias e seus processos de inclusão reforçam a heteronormatividade e potencializam os efeitos gerados pelo dispositivo da sexualidade (FOUCAULT, 2001a), intensificando a produção de discursos normalizadores o que, na escola, não será diferente. Nela, tais discursos ganharão forma num currículo pautado pela retórica de respeito e tolerância, especialmente a partir dos anos 1990.

Inspirada pela reforma educacional espanhola organizada pelo partido popular, ultraconservador, no início dos anos 90 , a educação brasileira tomou para si a concepção dos temas transversais e instituiu educação sexual como um dos temas a serem trabalhados nos PCNs. O fascículo sobre o tema Transversal Orientação Sexual, publicado em 1997, consolidou definitivamente a escolarização de uma educação para o sexo. (CÉSAR, 2009, p. 42).

Nesse panorama, os próprios sujeitos da diversidade sexual passam, respaldados pelos movimentos sociais, a reivindicar seu lugar na escola, usando, como estratégia, cada vez mais um dizer sobre si mesmo, uma espécie de outing da nossa época, em que não basta apenas revelar-se gay; antes, é preciso confessar a verdade sobre seu sexo e sua sexualidade e oferecer aos aparatos de

12 Vejam, por exemplo, a polêmica que tomou conta do Brasil acerca da distribuição do kit anti-homofobia, que mobilizou tanto os movimentos sociais, quanto os setores mais conservadores do país sobre o debate em torno da presença de LGBTs na escola e de como lidar com o preconceito em relação a esses estudantes. Sem querer entrar no mérito da questão, trazemos esse exemplo apenas para aludir a como tem sido discutida a relação entre homossexualidade e educação e de como isso tem constituído uma pauta nos movimentos sociais contemporâneos. 
governamento $^{13}$ (FOUCAULT, 2008b) insumo para o estabelecimento de uma certa conformação identitária do corpo, do sexo, da sexualidade. Com isso, esses sujeitos ajustam-se aos projetos educacionais normalizadores que estabelecem os princípios de viabilidade-moral-econômica dos corpos e de como esses corpos devem ocupar seus lugares a partir das categorias identitárias a eles conferidas.

Em vista disso e a despeito de seus importantíssimos ganhos jurídicos e políticos, observa-se que na exata proporção de suas conquistas, tais projetos educacionais tendem a reproduzir a lógica da normalização, promovida e disseminada socialmente como efeito do dispositivo da sexualidade (FOUCAULT, 2001a). Nesse sentido, no âmbito educacional, é importante ressaltar que a inserção dos "temas" gênero, sexualidade e diversidade não implica, necessariamente, instaurar a diferença no currículo e na escola. Grande parte dos projetos educacionais contemporâneos diz respeito ao acoplamento de temas "estrangeiros" nas práticas discursivas curriculares tradicionais, sem, contudo, questionar a norma curricular (CÉSAR, 2009). A ideia da simples inclusão de temas não convencionais no currículo deve ser problematizada, pois tal inclusão pode significar a normalização da diferença, como em geral ocorre em se tratando das dinâmicas de tolerância, a qual não desmonta o racismo, a misoginia ou a homofobia; ao contrário, reforça a presença de um centro normativo que será sempre branco, heterossexual, masculino (LOURO, 2003). A instauração da diferença na escola deve ser o ponto de partida para que haja um confronto, no interior das práticas escolares, entre a percepção normalizada dos corpos e da sexualidade e a existência de outros corpos, gêneros e experiências.

Entretanto, a maior parte dos projetos educacionais inspirados pela dinâmica das lutas identitárias não parece seguir nessa direção crítica e radical. No estrito contexto da lógica pela inclusão de novos sujeitos no universo educacional, os movimentos sociais reivindicam o direito à educação e a legislação garante tal direito e as instituições escolares devem cumprir a lei. Os agentes mobilizados para pensar a permanência dos novos sujeitos nas instituições escolares são, de forma crescente, os movimentos sociais (CÉSAR, 2010b). Por certo, não se trata de recusar essas importantes conquistas. Porém, cabe interrogar os projetos educacionais que vêm se estabelecendo desde a última década, a partir do princípio do direito dos múltiplos sujeitos abarcados por categorias sociais

13 A expressão "governamento" está sendo usada aqui na acepção que propõe Veiga-Neto (2002), justamente para marcar a distinção que Foucault faz entre o que são instâncias administrativas de governo e ações de governar. Desse modo, quando falamos em "governamento", ou "práticas de governamento" é para indicar, nesta pesquisa, que "[...] não são ações assumidas ou executadas por um staff que ocupa uma posição central no Estado, mas são ações distribuídas microscopicamente pelo tecido social; por isso soa bem mais claro falarmos em práticas de governamento." (VEIGANETO, 2002, p. 21). 
identitárias. A questão problemática é a seguinte: num modelo escolar identitário, a instituição continua a excluir o desconhecido, isto é, todos aqueles que ela considera como abjeção incompreensível (POCAHI; DORNELLES, 2010). No interior do modelo identitário, indivíduos e experiências inclassificáveis e ininteligíveis de corpo e de gênero permanecem por definição excluídos do universo escolar, ou nele são incluídos sob o preço de sua domesticação normalizada (SANTOS, 2010). Não por acaso, no contexto dos processos identitários de inclusão do outro, o que ocorre comumente é o processo despolitizador de "folclorização" dos grupos sociais e sujeitos, o qual se traduz, por exemplo, em datas comemorativas como o dia do negro, da mulher, do índio, etc. (LOURO, 2003). A escola moderna é uma instituição que não suporta o desconhecimento, é um espaço no qual os saberes e os sujeitos precisam ser inteligíveis para que sejam incluídos em seu plano curricular institucional (CÉSAR, 2009). Para Butler (2001), por outro lado, precisamos aprender a viver em um mundo mais aberto, o que implica a destruição das evidências e certezas, ou aprender a lidar com o desconhecido. Instaurar a diferença na escola significa a possibilidade de viver sem saber e a impossibilidade de dar respostas. Nessa perspectiva, o que importa é questionar até que ponto a escola é capaz de lidar com o não saber no âmbito do gênero e da sexualidade (LOURO, 2004). Diante disso, a indagação sobre o acontecimento da diferença nas escolas pressupõe a disposição de professoras e professores para não saberem mais as respostas, além do seu desejo de propor novas perguntas, sem as conhecidas verdades sobre os sujeitos - "o delinquente", "a histérica", "o homossexual", "o transexual" etc. (CÉSAR, 2009). Para experimentar outra lógica, professoras e professores precisam desejar produzir a capacidade para a liberdade, e isso requer elidir as fronteiras do pensamento binário e normativo (BRITZMAN, 1999). Em face disso, uma reflexão de inspiração foucaultiana sobre a estética da existência parece permitir justamente questionar os projetos educacionais do presente, em nome da possibilidade de acolhimento do desconhecido, isto é, do acolhimento de experiências e modos de vida não normativos em relação ao gênero e à sexualidade, salvaguardando-se, assim, novas dimensões da experiência humana, para além das fronteiras jurídico-políticas e identitárias.

Define-se assim um quadro polêmico de polarização. Por um lado, observam-se identidades novas e antigas constituindo os movimentos e as lutas políticas por direitos individuais e sociais. Por outro lado, observa-se a elaboração das críticas que demonstram os processos de exclusão, patologização, normalização e captura das práticas, experiências e estéticas nos processos de produção e funcionamento das identidades. Em vista deste impasse, os movimentos sociais LGBT (e também feministas), assim como os projetos educacionais a eles relacionados, tendem a não vislumbrar a possibilidade política de novas 
experiências e práticas de vida para além do universo semântico da identidade e do sujeito de direitos (VALE de ALMEIDA, 2009).

Sem pretender recusar, voltamos a repetir, a noção de sujeito de direitos e os ganhos jurídico-políticos que ela tem permitido obter, trata-se de pensar uma educação na qual a inclusão de todos os indivíduos questione criticamente os princípios de normalização que, tradicionalmente, estiveram envolvidos na definição do sujeito de direitos e de sua identidade, visando-se, assim, a dissolução radical da gênese mesma de todo processo de formação de abjeções, anomalias e anormalidades no universo educacional. A reiteração não crítica de problematizações educacionais que pressupõem o sujeito, uma identidade, um direito e uma ideia de cidadania entendida exclusivamente a partir das noções de identidade e de sujeito de direito, tende a encerrar os corpos, as práticas, as experiências educacionais, os prazeres, os modos de vida ou culturas sexuais no interior de processos de sujeição, os quais constituem a matéria e a ação dos processos de normalização em suas vertentes disciplinares e biopolíticas (CÉSAR, 2010a; LOURO, 2001).

Bem por isso, o que nos interessa é tentar mostrar como a teorização identitária, que pauta as ações dos movimentos sociais, bem como solda essas ações às políticas de Estado, continua implementando, constitutivamente e paradoxalmente, formas de exclusão da diferença a partir de suas estratégias de inclusão. Quer dizer, da forma como vemos, que essa pauta de reivindicações colocada atualmente ignora justamente aquilo que é considerado corpos-abjetos, vidas-abjetas, até porque tais abjeções podem inviabilizar a luta dos movimentos sociais, inclusive no campo educacional. Falamos, aqui, de multidões-corpos, multidões-vida, multidões queer (PRECIADO, 2011) que borbulham em outras águas, que requerem para si outras formas de existência, que se inscrevem em outros modos de vida. O segundo argumento desse trabalho tratará justamente dessa questão.

\section{Por uma ética/estética pós-identitária LGBT na educação}

Eu acredito que um dos fatores de estabilização será a criação de novas formas de vida, de relações, de amizades nas sociedades, a arte, a cultura de novas formas que se instaurassem por meio de nossas escolhas sexuais, éticas e políticas. Devemos não somente nos defender, mas também nos afirmar, e nos afirmar não somente enquanto identidades, mas enquanto força criativa. (FOUCAULT, 2004).

O segundo argumento que queremos estabelecer nesse trabalho refere-se à noção de ética/estética da existência (FOUCUALT, 2010a, 2010b). Para nós, 
essa ideia é importante pois com ela é possível provocar um tensionamento, uma espécie de torção em relação à noção de viabilidade-moral-econômica anunciada anteriormente. Por ela queremos nos referir, sob a inspiração de Foucault, a todo um conjunto de práticas que pretende apontar para outras possibilidades de vida diante dos projetos normalizadores de nossos corpos, práticas sexuais e afetivo-amorosas, bem como para a elaboração de caminhos possíveis inscritos não apenas numa luta contra as formas de dominação e exploração, mas também - e sobretudo na atualidade - contra as formas de sujeição (FOUCAULT, 1995). Desse modo, a noção de estética da existência pode estabelecer um deslocamento, uma espécie de distensão, um estiramento em relação aos mecanismos de governamento, bem como nos possibilitar o ensaio de outras constituições éticas/estéticas para, no plano do vivível, tentar entender os mecanismos de captura do viável. Como nos diz Foucault em seus últimos escritos, tal ideia pode potencializar um outro estado conosco mesmos, capaz, em toda sua força, de nos dar condições de criar outros modos de vida (FOUCAULT, 2010a, 2010b) e instaurar outras possibilidades corporais, sexuais, afetivo-amorosas e políticas (BUTLER, 2003, PRECIADO, 2002, 2008), a partir de como ousamos viver.

Parece-nos que uma ação política que se pauta nas lutas em busca de direitos individuais de cada uma das identidades que compõem o rol de sujeitos abrigados na etiqueta "diversidade sexual" acaba expurgando de seu conjunto corpos, práticas e prazeres que, de algum jeito, experienciam um projeto ético/ estético mais perturbador em relação às formas atuais de governamento da vida. Talvez não seja o caso, então, de pensar como seria possível, mesmo diante das conquistas jurídicas e civis já asseguradas pela teorização e luta identitárias, incluir todos os sujeitos sem submetê-los aos processos de normalização. Isso seria, quase, um paradoxo em si. Queremos nos desviar desse caminho uma vez que, da forma como concebemos, todo processo de inclusão sempre articulará, por outro lado, processos de normalização e, portanto, de aniquilamento da alteridade. $\mathrm{O}$ problema está, em vista disso, menos ligado à questão de como poderíamos incluir os sujeitos da diversidade sexual no mundo social e educacional para garantir-lhes direitos; e, mais, em como pensarmos formas de interrogação do sujeito identitário e de suas conformações anatomopolíticas ${ }^{14}$ e biopolíticas ${ }^{15}$ que

14 Cabe lembrar que a noção de anatomopolítica tem a ver com o momento em que Foucault (2001b) demonstra como um organismo torna-se alvo dos dispositivos disciplinares que agem sobre corpos individuais a partir do século XVII. Mais tarde, “[...] Foucault acrescentou às discussões desenvolvidas em torno do conceito de anátomo-política do corpo disciplinado individualizante as análises centradas em torno do conceito de biopolítica das populações, entendido como gestão estatal do corpo e da vida da espécie humana. (CÉSAR; DUARTE, 2009, p. 120).

15 A ideia de biopolítica aqui tem a ver com o momento em que Foucault passa a investigar os dispositivos de produção da sexualidade e, com isso, percebe que o sexo e a própria vida deixam de ser controlados por um conjunto de poderes que agia sobre comportamentos individualizados, 
o encerram e o individualizam como um corpo viável aos princípios da moral heteronormativa e do mercado neoliberal (SIERRA, 2013). Trata-se, pois, não “[...] em tentar liberar o indivíduo do Estado nem das instituições de Estado, porém nos liberarmos tanto do Estado quanto do tipo de individualização que a ele se liga" (FOUCAULT, 1995, p. 239), para que, ousadamente, possamos defender formas de vida não assujeitadas, não conformadas aos princípios neoliberais que romantizam e vendem a seguridade e o conforto como direito de/ para todos. Como diz o próprio Foucault (1995, p. 239): “Temos que promover novas formas de subjetividade através da recusa deste tipo de individualidade que nos foi imposto há vários séculos."

Nossa época tem sido marcada, de acordo com Foucault (1995), por lutas transversais que não se restringem a uma forma política e econômica de governo e que não objetivam um inimigo em comum, a saber, algo que nos ameaçaria num futuro virtual. Ao contrário, o inimigo de hoje é aquele imediato, que ameaça a cada um. Por isso, as lutas que marcam nosso tempo talvez precisassem fazer o questionamento do estatuto do indivíduo e das formas de governamento da individualização. Ao estabelecer uma distinção entre três tipos de lutas que têm marcado nossa história (lutas contra a dominação, lutas contra as formas de exploração e lutas contra as formas de sujeição), Foucault nos mostra como, na atualidade, se faz necessário lutar contra as formas de sujeição, mesmo que, evidentemente, as formas de dominação e exploração não tenham desaparecido. Gros (2010), na situação do curso Hermenêutica do Sujeito, de Michel Foucault, diz que é só nos anos 1980 que o autor francês determina claramente a oposição que deve ser feita ao Estado e, por consequência, aos seus processos geradores de normalização, individualização e identificação: "Trata-se precisamente das práticas de si, tomadas na dimensão relacional que ele havia tão bem descrito no tocante ao estoicismo romano" (GROS, 2010, p. 492).

Diante disso, o desafio que se coloca hoje é justamente não o da simples negação das políticas identitárias e de seus reconhecidos efeitos no combate à LGBTfobia e às violências de gênero tão assustadoramente presentes na realidade brasileira. Ao contrário, é juntar a essa forma de ação política outras alternativas capazes de ampliar o combate aos horrores de nossa época sem, contudo, desprezar formas de vida que não se reconhecem nessas políticas de inclusão identitária. Nesse sentido, a forma como essas políticas têm se apresen-

para, agora, serem conduzidos por um arsenal de práticas que visam a própria espécie em seus mais variados fenômenos populacionais. "A partir do século XIX, já não importava mais apenas disciplinar as condutas, pois também era preciso implantar um gerenciamento planificado da vida das populações. Assim, o que se produziu por meio da atuação específica do biopoder não foi mais apenas o indivíduo dócil e útil, mas a própria gestão calculada da vida do corpo social." (CÉSAR; DUARTE, 2009, p. 120). 
tado e operado pode inibir outras alternativas de viver o corpo e suas práticas, inclusive no caso da homossexualidade que, para Foucault, poderia se constituir em uma grande possibilidade de criar outros estilos de vida, outras escolhas de existência, como ele mesmo diz em uma de suas entrevistas:

A homossexualidade é uma ocasião histórica de reabrir virtualidades relacionais e afetivas, não tanto pelas qualidades intrínsecas do homossexual, mas porque a posição desse "de esguelha", as linhas diagonais que ele pode traçar no tecido social permitem fazer aparecer essas virtualidades. (FOUCAULT, 2010b, p. 351).

Nesta entrevista, intitulada "Da amizade como modo de vida" e publicada no jornal Gai Pied, n. 25, em abril de 1981, Foucault desenvolve a ideia da homossexualidade como mobilizadora de múltiplas relações que precisam ser desejadas, buscadas, inventadas, de maneira a constituir uma ascese, um modo de vida improvável, imprevisto, um modo de vida-outro, ao qual se poderia chegar por meio da amizade. Nesta entrevista, Foucault, poeticamente, chama atenção para como seria importante e necessário pensarmos a homossexualidade como algo que é preciso desejar, já que, por meio dela, seria possível reinventar-se, reduplicar-se, modular-se em múltiplas outras formas de relações, de existência, de vida. A homossexualidade, nesse sentido, antes de ser a manifestação de um desejo, seria algo de desejável, algo que precisaria ser buscado. Diz ele:

O problema não é descobrir em si a verdade sobre seu sexo, mas antes usar sua sexualidade para chegar a uma multiplicidade de relações. E está aí, sem dúvidas, a verdadeira razão pela qual a homossexualidade não é uma forma de desejo, mas algo de desejável. Temos, então, que nos aferrar à ideia de nos tornarmos homossexuais e não nos obstinarmos em reconhecer que somos homossexuais. (FOUCAULT, 2010b, p. 348).

Evidentemente que quando o autor fala em "homossexualidade como algo de desejável" não se refere ao ato sexual em si, mas a um modo de vida homossexual, a um estar-no-mundo homossexual ainda em devir, a um trabalho sobre si mesmo que levaria à invenção de algo ainda impensável, inimaginável, à transformação de si em algo que ainda não se é. Por isso, nos restaria “[...] avançar sobre uma ascese homossexual que faria com que trabalhássemos sobre nós mesmos e inventássemos, não digo descobríssemos, uma maneira de ser 
ainda improvável." (FOUCAULT, 2010b, p. 350). E, ainda, segundo o pensador francês, esse trabalho de invenção de si pelas modulações que a busca por uma ascese homossexual pode provocar seria potencializado por meio de relações de amizade ${ }^{16}$, escapando, assim, "[...] das duas fórmulas feitas: a do puro encontro sexual e a da fusão amorosa das identidades" (FOUCAULT, 2010b, p. 350).

Parece-nos, frente às palavras de Foucault, que as lutas atuais deveriam se constituir muito menos tendo como horizonte o reconhecimento de uma identidade do verdadeiro sujeito homossexual, muito menos o requerimento apenas de direitos de igualdade, muito menos, sobretudo, o desejo de normalização da homossexualidade. Tudo isso, para ele, só reforçaria os mecanismos de governamento, bem como seria "[...] uma maneira de cair na grande malha da instituição." (GROS, 2010, p. 492). Ao contrário, para Foucault, se quisermos inventar formas de resistir temos que buscá-las em outros lugares, a saber, na invenção de nós mesmos por meio de práticas de si que nos levariam à criação de uma outra ética/estética, ou seja, de um outro modo de vida.

Isso significa que recorrer a Foucault e sua teorização sobre a ética da existência pode fornecer elementos muito significativos para a crítica da situação apresentada acima. Os últimos estudos de Foucault são capazes, vemos assim, de indicar grandes possibilidades de se fazer a crítica ao sujeito de direito, bem como à noção de identidade que, até então, tem se constituído como tônica na agenda dos movimentos sociais, do Estado e dos eventos educacionais ligados a eles. No campo educacional, pensar em termos de ética/estética de existência pode nos dar a chance de exercitar a constituição de um espaço diferente, especialmente diante de uma época que bombeia respeito e tolerância, mas que conforma isso como estratégia de enredamento anátomo-bio-político de corpos, práticas e prazeres.

Mesmo que algumas experiências educacionais específicas já tenham abordado as experiências homoeróticas e homoafetivas, a heterossexualidade permanece como o centro organizador do governo da sexualidade na escola. Quando algumas barreiras são ultrapassadas, o "tratamento pedagógico" terá base no problemático e intolerável conceito de tolerância. (CÉSAR, 2011, p. 276).

Em vista desses processos normalizadores que interceptam não somente os sujeitos sociais, mas também os sujeitos escolares, os estudos finais de Foucault alcançam um potencial revigorante, pois nos convidam a pensar nossos

16 Sobre amizade em Foucault ver os estudos de Ortega (1999, 2002). 
corpos, nossas práticas, nossos prazeres como artífices da beleza de nossa própria existência, nós mesmos como "artistas" de nossa própria vida. Essa trilha de investigação poderá criar outras teorizações, seja para campo político, seja para o campo educacional, em que a defesa por formas de vida não conformadas aos mecanismos de governamento contemporâneos poderá se dar, justamente, no momento mesmo em que, ao pôr em xeque sua compulsória viabilidade-moral-econômica, tais vidas possam buscar outras vivibilidades (SIERRA, 2013) e, com isso, tentar constituir outros modos de viver o corpo e suas práticas.

O objetivo, portanto, foi o de tentar mostrar como nosso presente engendra formas de governamentalidade que se atritam com possibilidades de invenção de outros modos de vida, bem como aludir à chance que temos de construir um caminho diferente. A partir desse pensamento talvez seja possível, com maior intensidade, mostrar como as teorizações identitárias, que promovem a celebração da diversidade sexual e de suas identidades legitimadas, que brindam à exaustão o culto individualista e os interesses particulares, que festejam a toda hora suas conformações decifráveis, inteligíveis e ajustáveis à moral heteronormativa e aos princípios do mercado neoliberal, encontram dificuldade em mostrar rotas de saída frente à captura e controle das subjetividades. Pensar, portanto, a partir da noção de estética da existência possibilitaria mostrar, ao contrário, que a prática de si

[...] não se trata de modo algum de idolatria ou auto-adoração beata. Simplesmente, de si para consigo é uma questão de elevação. Não se trata tampouco de narcisismo: Foucault não cessa de insistir nesse princípio de austeridade: a fruição de si mesmo não é da ordem do prazer, mas visa o sentido jurídico de uma posse completa, de uma imanência a si total e perfeitamente igual. (GROS, 2008, p. 135).

Desse modo, vemos como pertinente pensar nossa atualidade a partir desses estudos derradeiros de Foucault, especialmente diante, na contemporaneidade, da radicalização das identidades, bem como da celebração da diversidade sexual e de seus sujeitos - agora, sujeitos de direito. Em vista disso, pensamos que o referencial foucaultiano sobre a estética da existência pode fornecer elementos para uma crítica da razão identitária, da noção de sujeito de direito, das retóricas de diversidade sexual e, assim, contribuir - inclusive em trabalhos futuros - para a introdução de uma teorização político-educacional mais ampla em torno das lutas e dos direitos dos sujeitos LGBT que pressupusesse, dessa vez, liberar-se das "máscaras visíveis do homossexual [para] procurar definir e criar um modo de vida." (FOUCAULT, 2010b, p. 351). 


\section{REFERÊNCIAS}

BRITZMAN, Deborah. Curiosidade, sexualidade e currículo. In: LOURO, G. (Org.). $O$ corpo educado. Pedagogias da sexualidade. Belo Horizonte: Autêntica, 1999. p. 83-111. BUTLER, Judith. Bodies that matter. On the discursive limits of "sex". New York: Routledge, 1993.

. Corpos que pesam: sobre os limites discursivos do "sexo". In: LOURO, Guacira Lopes. (Org.). O corpo educado. Pedagogias da sexualidade. Belo Horizonte: Autêntica, 1999; p. 151-172.

. La cuestión de la transformación social. In: BECK-GERNSHEIM, E.; BUTLER, J. PUIGVERT, L. Mujeres y transformaciones sociales. Barcelona: El Roure, 2001. p. 07-30.

. Problemas de gênero: feminismo e subversão da identidade. Trad. Renato Aguiar. Rio de Janeiro: Civilização Brasileira, 2003.

CÉSAR, Maria Rita de Assis. As novas práticas de governo na escola: o corpo e a sexualidade entre o centro e as margens. In: BRANCO, Guilherme Castelo; VEIGA-NETO, Alfredo. (Orgs.). Foucault: filosofia \& política. Belo Horizonte: Autêntica, 2011.

. (Des)governos... biopolítica, governamentalidade e educação contemporânea. ETD. Educação Temática Digital, v. 12, p. 224-2412010a.

. Governando corpo e sexualidades na escola. In: REUNIÃO ANUAL DAANPEd, 33. Anais..., 2010b. p. 01-12. 1 CD-ROM.

. Gênero, sexualidade e educação. Notas para uma 'epistemologia'. Educar em Revista, n. 35, p. 37-52, 2009.

CÉSAR, Maria Rita de Assis; DUARTE, André. Governo dos corpos e escola contemporânea: pedagogia do fitness. Educação e Realidade, v. 34, n. 2, p. 119-134, 2009.

FACHINNI, Regina. Sopa de Letrinhas: movimento homossexual e produção de identidades coletivas nos anos 90. Rio de Janeiro: Garamond, 2005.

FOUCAULT, Michel. A hermenêutica do sujeito. 3. ed. São Paulo: Martins Fontes, 2010a.

. Da amizade como modo de vida. In:

a Política. Rio de Janeiro: Forense Universitária, 2010b. Ditos \& Escritos. Vol. VI. Repensar . Em defesa da sociedade. São Paulo: Martins Fontes, 2002a.

. História da Sexualidade. A vontade de saber. V. 1. 14. ed. Rio de Janeiro: Graal, 2001a.

. Nascimento da biopolítica. São Paulo: Martins Fontes, 2008a.

. O sujeito e o poder. In: RABINOW, Paul; DREYFUS, Hubert. Foucault. Uma trajetória filosófica. Para além do estruturalismo e da hermenêutica. 1. ed. Rio de Janeiro: Forense Universitária, 1995. 
SIERRA, J. C.; CÉSAR, M. R. A. Governamentalidade neoliberal e o desafio...

. Segurança, território, população. São Paulo: Martins Fontes, 2008 b.

. Vigiar e Punir: nascimento da prisão. 24. ed. Petrópolis: Vozes, 2001 b.

GADELHA COSTA, Sylvio de Sousa. Governamentalidade neoliberal, teoria do capital humano e empreendedorismo. Educação e Realidade, v. 34, n. 2, p. 119-134, 2009.

GROS, Frédéric. O Cuidado de si em Michel Foucault. In: RAGO, Margareth; VEIGA-NETO, Alfredo. (Orgs.). Figuras de Foucault. Belo Horizonte: Autêntica, 2008; p. 127-138.

. Situação do Curso. In: FOUCAULT, Michel. A hermenêutica do sujeito. Curso do Collège de France (1981-1982). São Paulo: Martins Fontes, 2010. p. 453-493.

LAURETIS, Teresa de. Queer theory: lesbian and gay sexualities. An introduction. Differences. A Journal of feminist cultural Studies, v. 5, p. 04-18, 1991.

LOURO, Guacira Lopes. Currículo, gênero e sexualidade. O "normal”, o "diferente” e o "excêntrico". In: LOURO, G. L.; NECKEL, J. F.; GOELLNER, S. V. (Orgs.). Corpo, gênero e sexualidade. Um debate contemporâneo na educação. Petrópolis: Vozes, 2003. p. 41-52.

. Gênero, sexualidade e educação: uma perspectiva pós-estruturalista. 2. ed. Petrópolis, RJ: Vozes, 1998.

. Gênero, história e educação: construção e desconstrução. Educação e Realidade, v. 20, n. 2, p.101-132, jul./dez. 1995.

. Teoria queer: uma política pós-identitária para a educação. Revista de Estudos Feministas, Florianópolis, v. 9, n. 2, 2001.

. Um corpo estranho. Ensaios sobre sexualidade e teoria queer. Belo Horizonte: Autêntica, 2004.

ORTEGA, Francisco. Amizade e estética da existência em Foucault. Rio de Janeiro: Graal, 1999.

. Genealogias da Amizade. São Paulo: Iluminuras, 2002.

POCAHI, Fernando; DORNELLES, Priscila. Um corpo entre o gênero e a sexualidade: notas sobre educação e abjeção. Instrumento. R. Est. Pesq., v. 12, n. 2, p. 125-135, 2010.

PRECIADO, Beatriz. Terror anal: apuntes sobre los primeros días de la revolución sexual. In: HOCQUENGHEM, Guy. El deseo homosexual. Espanha: Melusina, 2009.

. Manifesto contra-sexual. Prácticas subversivas de identidad sexual. Madri: Obra Prima, 2002.

. Multidões queer. Notas para uma política dos "anormais." Revista de Estudos

Feministas, Florianópolis, v. 19, n. 1, 312, p. 11-20, jan./abr. 2011.

. Testo yonqui. Madri: Espasa, 2008. 
RICH, Adrianne. Compulsory heterosexuality and lesbian existence. In: ABELOVE, H.; BARALE, M. A.; HALPERIN, D. M. (Ed.). The lesbian and gay studies reader. New York: Routledge, 1993. p. 227-254.

RUBIN, Gayle. Thinking sex. Notes for a radical theory of the politics of sexuality. In: ABELOVE, H.; BARALE, M. A.; HALPERIN, D. M. (Ed.). The lesbian and gay studies reader. New York: Routledge, 1993. p. 3-44.

SANTOS, Dayana Brunetto C. Cartografias da transexualidade: a experiência escolar e outras tramas. Dissertação (Mestrado em Educação) - Universidade Federal do Paraná, Programa de Pós-Graduação em Educação. Curitiba, 2010.

SIERRA, Jamil Cabral. Marcos da vida viável, marcas da vida vivível: O governamento da diversidade sexual e o desafio de uma ética/estética pós-identitária para a teorização político-educacional LGBT. Tese (Doutorado em Educação) - Universidade Federal do Paraná. Curitiba, 2013.

SPARGO, Tasmim. Foucault y la teoría queer. Barcelona: Editorial Gedisa, 2007.

. Foucault e a teoria queer. Rio de Janeiro: Pazulin; Juiz de Fora: Ed. UFJF, 2006.

VALE de ALMEIDA, Miguel. Ser mas não ser, eis a questão. O problema persistente do essencialismo estratégico. Working Paper CRIA, 1, Lisboa, 2009.

VEIGA-NETO, Alfredo. Coisas de governo... In: RAGO, Margareth; ORLANDI, Luiz B. Lacerda; VEIGA-NETO, Alfredo. (Orgs.). Imagens de Foucault e Deleuze. Ressonâncias nietzschianas. Rio de Janeiro. DP\&A, 2002. p. 13-34.

WITTIG, Monique. One is not born a woman. In: ABELOVE, H.; BARALE, M. A.; HALPERIN, D. M. (Ed.). The lesbian and gay studies reader. New York: Routledge, 1993. p. 103-109.

Texto recebido em 09 de maio de 2014.

Texto aprovado em 19 de maio de 2014. 